\title{
El inicio de una nueva etapa en la comunicación política argentina: el primer debate presidencial televisado
}

The beginning of a new stage in Argentina's political communication: the first televised presidential debate

\author{
Marina Acosta \\ Instituto de Estudios de América Latina y el Caribe; \\ Facultad de Ciencias Sociales: Universidad de Buenos Aires/ \\ Universidad Nacional Arturo Jauretche (Argentina) \\ maruacosta@yahoo.com.ar

\section{Carlos Campolongo} \\ Facultad de Ciencias Sociales; Universidad de Buenos Aires/ \\ Universidad Nacional de Lomas de Zamora (Argentina) \\ cmcampolongo@fibertel.com.ar
}

\section{Resumen}

En 2015, por primera vez en la Argentina hubo un debate presidencial imperfecto (faltó uno de los principales candidatos) y, finalmente, otro "frente a frente" que reunió a los dos que 
quedaron seleccionados para el balotaje. Mauricio Macri y Daniel Scioli abrieron una práctica ausente en la democracia argentina, aunque institucionalizada en otros países del mundo. Presentamos algunas características destacadas de ese acontecimiento fundante para la comunicación política argentina. Para construir los datos del análisis utilizamos fuentes secundarias y primarias, entre las cuales destacamos las entrevistas en profundidad que hemos realizado a organizadores del evento y a asesores que participaron en los equipos de campaña de los candidatos. Para contextualizar la problemática recurrimos al marco teórico que ofrece la comunicación política.

Palabras clave: debate presidencial; campaña electoral; comunicación política; Argentina.

\section{Abstract}

In Argentina for the first time, in 2015, there was an imperfect presidential debate (one of the main candidates was missing) and, finally, another "face to face" that brought together the two who were selected for the ballotage. Mauricio Macri and Daniel Scioli opened a practice absent in the Argentine democracy although institutionalized in other countries of the world. We present some outstanding features of that founding event for Argentine political communication. In order to construct the data of the analysis we use secondary and primary sources, among which we emphasize the in-depth interviews that we have realized to organizers of the event and to advisors who have participated in the candidates' campaigns. To contextualize the problem, we turn to the theoretical framework offered by political communication.

Key words: presidencial debate; electoral campaign; political communication; Argentina.

A diferencia de lo que ocurre en otras democracias del mundo, donde la práctica del debate presidencial está consolidada desde hace varias décadas, en la Argentina nunca había acontecido. La etapa de los debates presidenciales en el país se inauguró con dos instancias en 2015: los domingos 4 de octubre y 15 de noviembre. En la transmisión precursora para la primera vuelta, cinco de los seis candidatos estuvieron presentes cumpliendo con los compromisos firmados con la entidad organizadora.

El debate parecía impostergable, hasta que el candidato oficial Daniel Scioli, del Frente para la Victoria (FpV), que lideraba las encuestas de opinión incumplió lo acordado mediante un acta de compromiso entre los candidatos, argumentando que no necesitaba discutir sus propuestas con otros candidatos en televisión, porque ya las había presentado públicamente a la 
ciudadanía. Interpretado por los observadores como una excusa para no arriesgar la performance que iba obteniendo en los sondeos electorales. Sin él, el resto de los precandidatos coincidió el domingo 4 de octubre en la Facultad de Derecho de la UBA en lo que fue un debate imperfecto.

Hemos decidido aportar nuestra visión sobre este fenómeno inédito en la democracia argentina. Nuestro objetivo general es examinar cómo se desarrolló y trascendió un acontecimiento mediático fundante para el país. En este sentido, creemos que se trata de un buen prisma que nos permite reflexionar sobre las determinaciones que fijó el contexto sociopolítico y que funcionó como dispositivo analizador de la cultura política y de los medios de comunicación masiva. Los objetivos específicos el trabajo son: 1. reconstruir la coyuntura sociopolítica donde tuvo lugar el debate; 2. describir las características particulares que adquirió el debate televisado que se realizó antes de la segunda vuelta; 3 . identificar las estrategias argumentativas utilizadas por los candidatos; 4 . evaluar la performance de cada uno de los candidatos en el acontecimiento mediático.

Dejamos en claro que no es nuestra finalidad examinar los efectos que este tuvo en la intención del voto, ni el análisis exhaustivo del discurso (stricto sensu) de los candidatos, propósitos perseguidos, en general, por las investigaciones de este campo de estudios (Isolatus, 2011). Dicha línea de trabajo implicaría utilizar metodologías de investigación que exceden nuestra preocupación.

Nuestro corpus de análisis se basa en entrevistas realizadas a informantes clave y en el propio producto audiovisual que también hemos transcripto. Optamos por realizar un análisis de contenido (AC) del debate presidencial con la propuesta de realizar un primer acercamiento general a este acontecimiento, que ha tenido un alto valor simbólico.

EI AC es una metodología destinada a formular, a partir de ciertos datos, inferencias reproducibles y válidas que puedan aplicarse a un contexto (Krippendorf, 1990: 28). Utiliza técnicas de medida que pueden ser cualitativas (lógicas que se basan en combinación de categorías) y cuantitativas (estadísticas que se basan en recuento de unidades) para elaborar datos relevantes sobre las condiciones en que se han producido ciertos textos. Por cierto, a través de este método se puede estudiar cómo se presentan los mensajes comunicacionales para luego establecer inferencias con sus contextos sociales y políticos. Para construir los datos del análisis también se ha recurrido a fuentes primarias, entre las cuales destacamos las entrevistas en profundidad que hemos realizado a organizadores de Argentina Debate y a asesores que participaron en los equipos de campaña de los candidatos.

Recurrimos al marco teórico de la comunicación política, que nos permite abordar la importancia de los debates televisivos para las democracias en general (Canel, 2008; del Rey Morató, 2006; Luengo, 2011; Manin, 1992; Plasser y Plasser, 2002) y para las latinoamericanas en particular (Crespo y del Rey Morató, 2013; Ruiz y Alberro, 2012; Waisbord, 1997). 
La investigación se estructura de la siguiente manera: 1. estado de la cuestión; 2. enfoque conceptual; 3. análisis del acontecimiento televisado; 4. conclusiones provisionales.

Con este trabajo intentamos iniciar una línea de trabajo en nuestro país, focalizada en un nuevo objeto de estudio que hasta el presente no ha podido desarrollarse dado la inexistencia de tradición en debate presidencial.

\section{Estado de la cuestión}

El debate televisivo constituye una oportunidad ofrecida a la ciudadanía para su involucramiento en la discusión pública de ideas, imágenes, proyectos y programas, fortaleciendo de esa manera la democracia. La literatura advierte que en tiempos de personalización o mejor hiperpersonalización de la política (Castells, 2010; Manin, 1992), la lógica que domina a los debates televisivos toma la forma de una carrera de caballos (horserace); o sea, de una competencia (Hershey, 2001; Reinemann y Wilke, 2007). Política y televisión se fusionan en la media politik (Peri, 2004). La intervención de la televisión potencia más la emocionalidad y afectos y efectos de personas, grupos y sociedad en general.

Los debates televisivos reúnen una serie de características importantes: 1. proveen a los votantes la oportunidad de atender directamente a los candidatos y conocer de cerca su posición respecto a los temas de campaña; 2 . dada la naturaleza de la televisión como medio masivo de comunicación, alcanzan segmentos de electores que, por lo general, no se exponen a la información política; 3. permite una impresión más o menos espontánea de conductas, gestos y temperamentos frente a lo imprevisible que puede emerger en la polémica, una interpretación de la prosaica -derivación de la disciplina conocida como proxémica- "en directo", vinculada a lo estético como dimensión viva de lo real que está aconteciendo; 4. el formato genera a su vez mucha información mediática que estimula de forma indirecta la discusión política entre los ciudadanos, en mucha mayor medida que cualquier evento concreto de campaña (Lazarsfeld et al., 1960; Luengo, 2011; Luengo y Marín, 2009; McKinney y Carlin, 2004; Mandoki, 1994). Este último rasgo es interesante, pues nos permite afirmar la idea de que al capturar la atención de los medios de comunicación, el debate televisivo hace que el resto de las actividades de campaña queden algo relegadas (Canel, 2008).

El presidencialismo característico de los sistemas políticos latinoamericanos ofrece más incentivos para estrategias de campaña centradas en el líder y los medios, en comparación con las estrategias de los sistemas parlamentarios (Plasser y Plasser, 2002). En nuestro país, dicho presidencialismo se ha acrecentado por el dominio de la "personalización de la política", concomitante con la "licuefacción" de los partidos políticos tradicionales -sobre todo después de la crisis global de 2001-, con falta de perdurabilidad de las alianzas electorales, proliferación de 
los flash parties y el incremento de la tendencia a la "volatilidad" del voto. Esto, sumado a culturas políticas personalistas, ha llevado a que en la región el foco de las campañas se haya trasladado desde los mítines y las concentraciones masivas a eventos audiovisuales guionados y debates televisados (Waisbord, 1997). En la coyuntura actual, también en la arena de las redes sociales (Castells, 2010; Gutiérrez Rubí, 2015).

Argentina llega muy tarde a la ola de debates electorales en América Latina (Ruiz y Alberro, 2012). La falta de raigambre de tal práctica en la democracia argentina, particularmente, se relaciona con su cultura política y con la débil interpelación social hacia la clase política.

\section{El debate político televisado en Argentina}

Desde la vuelta a la democracia en nuestro país en 1983, hubo varios intentos, sin suerte, para que los candidatos presidenciales participaran de un "duelo" televisado. No se dio en la primera elección de este período entre el candidato de la Unión Cívica Radical (UCR) Raúl Alfonsín e Italo Luder, del Partido Justicialista (PJ), que hasta ese entonces nunca había sido derrotado en una elección nacional. Al respecto cabe indicar que el "adagio" que se instaló, como prejuicio, fue que el candidato que va primero en las encuestas no otorga lo que subjetivamente, desde un candidato, se consideraría una "gracia" o "concesión" a favor de sus contrincantes. Se ignoran, así, las obligaciones propias de un sistema democrático a través del debate de ideas por parte de quienes aspiran a presidir una Nación.

Este escenario caracterizado por la ausencia de discusiones presidenciales televisadas reconoce, sin embargo, un punto de inflexión. A pesar de que no se enfrentaron candidatos presidenciales, la opinión pública argentina recuerda la primera gran discusión televisada que protagonizaron en 1984 el entonces canciller Dante Caputo (UCR) y el senador Vicente Saadi (PJ), ante el plebiscito convocado para un acuerdo con Chile por el Canal de Beagle. Se trató de un verdadero "suceso televisivo" que paralizó al país.

En el nivel provincial, el debate televisivo se dio entre aspirantes a la gobernación de la provincia de Buenos Aires, distrito con mayor número de electores del país: en 1987 se enfrentaron Antonio Cafiero (PJ) y Juan Manuel Casella (UCR). Este ejemplo cundió con el tiempo en algunas provincias. También hubo debates conjuntos de precandidatos presidenciales de diferentes partidos o que disputaban internas en los propios.

En 1989, Carlos Menem -candidato a la Presidencia por el PJ- lideraba las encuestas en intención de voto. Eduardo Angeloz (UCR), aceptó un debate con su contrincante que se realizaría en el programa televisivo Tiempo Nuevo, promovido por su conductor, el polémico periodista Bernardo Neustadt. Menem dejó "plantado" a Angeloz. El periodista decidió continuar con la emisión con primeros planos repetidos de la silla vacía en la que debía sentarse el 
candidato del justicialismo. Esa astucia comunicacional construyó un ícono perdurable que los argentinos recordarían elección tras elección. El síndrome de la "silla vacía" rememoraba la negativa de los candidatos que se imponían en los sondeos, a discutir sus propuestas de gobierno con los otros candidatos. Empero, Menem ganó la elección presidencial.

Una nueva frustración ocurrió en 1995 cuando el entonces presidente Menem también se negó a debatir con el candidato de la centroizquierda, José Octavio Bordón, que prometía ponerle fin a los efectos nefastos de la aplicación de las recetas neoliberales que se habían multiplicado por doquier en la economía argentina. Para las elecciones de 1999, los candidatos del bipartidismo nacional dominante tampoco se pusieron de acuerdo, a pesar de que los candidatos Fernando de la Rúa (UCR) y Eduardo Duhalde (PJ) habían manifestado públicamente la intención de confrontar propuestas en un espacio televisivo. Los equipos de campaña fracasaron en el intento.

En 2003, y a contramano de la estrategia que históricamente venía aplicando, Menem -ganador de la primera vuelta que tenía pocas chances de lograr un tercer mandato- desafió a su contrincante Néstor Kirchner a enfrentarse por televisión. La negativa del entonces gobernador de la provincia de Santa Cruz fue contundente, pues en aquel entonces dijo que el ex presidente tenía "poca autoridad moral" para convocar a la polémica (1).

\section{Marcos conceptuales}

\section{Nueva dramaturgia política}

Según las épocas, la política (como acción) siempre estuvo ligada a cierta dramaturgia teatral. Entendida como un arte y una técnica de componer o poner en escena la acción política. En ella, estructuralmente pueden considerarse ciertas invariantes características del líder, jefe, político o militar, con respecto a los gobernados o seguidores a lo largo de la historia. Los modos han tenido tipologías múltiples. Contemporáneamente, la política parece no poder diferenciarse del estilo comunicacional imperante en nuestras sociedades de la mediatización general (Verón, 1997).

Estas características convocan, cada vez más, a expertos para la comunicación política en la campaña de un candidato: actores, directores teatrales, cinematográficos y periodistas profesionales como expertos en coaching (entrenamiento) mediático. El coaching para un debate presidencial incluye una especie de manual de técnicas de argumentación y persuasión bajo presión y está diseñado para "controlar" la tensión escénica. Prepara al postulante también para detectar fallas en exposiciones del rival y encontrar la manera exacta para refutarlas. 
Además, participan como asesores de los candidatos otros profesionales autónomos, no orgánico-partidarios, consultores en marketing político estratégico, encuestadores, versados en focus groups (grupos de enfoque) y spin doctors (una entidad o persona encargada de la orquestación de propaganda para influir en la opinión pública), entre otros. De esta manera se extiende el estilo de la american campaigning que fue imponiéndose también en Europa y el resto del mundo y que experimenta con metodologías propias de la publicidad y el marketing comercial. La última puesta en práctica es la story telling que proviene de esta disciplina. Al no poder diferenciarse bien las marcas, se construye una historia alrededor de la misma.

La comunicación es la condición del funcionamiento de la democracia, lo que nos lleva a advertir que cuando nos referimos a ella incluimos a los medios y los sondeos de opinión pero también el modelo cultural favorable al intercambio entre las élites, los dirigentes y los ciudadanos (Wolton, 1999: 90). En ese contexto florece la democracia de audiencia como un tipo ideal de democracia centrada en los medios (Manin, 1992). En términos generales, se trata de la idea de que los votantes tienden cada vez más a votar a la persona y los temas que ellos encarnan. De esta manera, las relaciones entre representantes y representados quedan configuradas por las formas de la comunicación mediática: los medios imponen sus variadas lógicas a la política y los actores políticos se ven obligados a jugar con las reglas que impone el juego de los medios (Castells, 2010).

Es la dimensión dramatúrgica de la política como espectáculo junto a la democracia de audiencias la que también vedetiza al político, protagonista como tipo de "celebridad" homologable al star system cinematográfico. Esto permite generar corrientes empáticas, vínculos afectivos con alguna dificultad para apelar más consistentemente a la argumentación racional.

Actualmente, la "popularidad" es la condición que se toma en cuenta para la selección de candidatos de una elección. Al ceder ante los outsiders, llegan a la política ciertas personalidades que no han cumplido un cursus honorum (carrera política o escalafón de responsabilidades públicas en la antigua Roma). Por caso, sabemos que el trampolín de Macri antes de fundar el PRO fue el mundo de los negocios familiares y la presidencia del popular club de fútbol Boca Juniors, sin nexo estable con ningún partido político. Similar a su contrincante Scioli, proveniente de la experiencia mercantil heredada de su padre y su carrera deportiva como motonauta.

\section{El espectáculo político}

El político se transforma en una pura objetivación de todo aquello que agrada (o disgusta) a los observadores del espectáculo político (Edelman, 1991). Los medios llevan a la fetichización de los liderazgos, obligando a que se produzca una restricción en la exposición de propuestas 
políticas o plataformas electorales con la consecuente simplificación de los mensajes políticos. En términos dramatúrgicos, el político se vuelve actor y debe construir/desarrollar su carisma audiovisual (Landi, 1992) o telegenia. Se trata, entonces, de la versión mediática del antiguo carisma que se concreta en la capacidad comunicativa del líder político, una capacidad estructurada y centrada en una serie de habilidades que van desde su aspecto físico, su gestualidad, su vestuario, hasta la capacidad para entretener o divertir. La política se ve obligada, pues, a adoptar nuevos decorados; el político debe manejar diferentes registros gestuales y discursivos según el género y el medio que lo convoque. Se apela a potenciar rasgos y códigos que acerquen al electorado.

Esto nos lleva a hacer referencia a la democracia de la emoción, pues entendemos que la representación política desaparece en la instantaneidad de la comunicación en beneficio de una cruda y desnuda presentación de acontecimientos (Virilio, 1996). A esta democracia centrada en la emoción ha contribuido el papel cada vez más penetrante de la televisión en la política dando lugar a la videopolítica (Landi, 1992; Muraro, 1998; Sartori, 1998; 2003); es decir, al aspecto público de la política que impone sus reglas sobre las del discurso político, generando al mismo tiempo una videodependencia (Sarlo, 1997; Sartori, 1998). En la televisión valen las formas: el cómo se dice se impone al qué se dice. De allí la máxima gobernar es hacer creer que conduce a la necesidad de que contenidos políticos encuentren formas de escenificación y simbolización mediática (Debray, 1999).

Finalmente, sostenemos que el debate televisivo constituye un acontecimiento mediático producido para la televisión. Se trata de un pseudoevento; es decir, de un hecho provocado cuyo objetivo es lograr la visibilidad mediática, dado que su éxito está sujeto a la difusión que alcance. Se trata, en síntesis, de una puesta en escena planificada que intenta mostrarse como la misma realidad. La idea repone al simulacro de Baudrillard (2001).

\section{Jueces del debate: la opinión pública discursiva y agregada}

No conviene pasar por alto el rol que juega la opinión pública (OP) en cualquier proceso electoral. Sabemos pues que ella representa el elemento de decantación de la comunicación política. En un intento por superar las definiciones rígidas en torno a la opinión pública, Víctor Sampedro ha propuesto abordarla desde su dimensión discursiva y desde su dimensión agregada. La opinión pública discursiva refiere al proceso colectivo donde las voluntades individuales deliberan y se condicionan entre sí mediante actos comunicativos. Se trata de la conversación cotidiana de la sociedad civil (opinión no institucionalizada) que activa, a su vez, un proceso de argumentación pública que muchas veces cristaliza en titulares de medios, sondeos o resultados electorales. La opinión pública agregada, en cambio, resulta de la suma de opiniones individuales; en ella priman los números/resultados por sobre los argumentos. Es 
estrictamente cuantitativa y es la que prevalece en las democracias delegativas, dado que en ellas la opinión que predomina es la demoscópica (O’Donnell, 1994). Por cierto, la opinión pública discursiva cristaliza en la opinión pública agregada (Sampedro, 2000: 20; Sampedro y Resina, 2010: 144).

La distinción entre una y otra nos resulta pertinente y funcional a nuestro análisis, dado que creemos que los debates televisivos constituyen un aporte sustantivo para la formación de la OP discursiva y, consecuentemente, de la OP agregada que es el objetivo final de todo debate entre candidatos.

\section{Análisis}

El kirchnerismo libró durante sus años de gobierno distintas disputas con diferentes sectores de la sociedad civil. Un grupo de ONG con alto perfil nacional e internacional (Poder Ciudadano, Asociación por los Derechos Civiles, CIPPEC) criticaban la "cerrazón informativa" y la "falta de transparencia" de la administración. La presentación de amparos judiciales de estas contra el Estado obtuvo distintos fallos favorables y algunas causas llegaron hasta la Corte Suprema de la Nación.

La tensión con la denominada prensa hegemónica también será recordada. Tal conflicto se inició durante 2008, en oportunidad de la normativa que gravaba las exportaciones agrícolas (Resolución 125, más conocida como "retenciones móviles"). La prensa de referencia (Clarín y La Nación) tomó posición por el sector de "el campo" y se libró una disputa comunicacional con el kirchernismo que se mantuvo hasta el final del mandato de Cristina Fernández (Blaustein, 2013; Campolongo et al., 2009). Se inaugura a partir de aquí un síntoma de época que va radicalizando posiciones: la denominada "grieta", que operó también como pivote discursivo en el camino hacia el debate.

Por otra parte, el marco socioeconómico que tuvo como telón de fondo la elección presidencial de 2015 estaba dominado, en el plano internacional, por la crisis política y económica del principal socio comercial de Argentina, Brasil y la caída en el precio de los commodities. A nivel nacional, a los altos niveles de inflación se sumaba el descrédito de los índices oficiales del INDEC, los problemas para acceder al financiamiento externo con altas tasas de endeudamiento internacional y muchas dudas sobre la capacidad de crecimiento del país con una cada vez más preocupante estanflación.

El desgaste sufrido por la presidencia de Cristina Fernández (2007-2015), del partido FpV fue inevitable (2). Poco a poco el kirchnersimo había descuidado su agenda republicana y con ello su agenda distribuitiva, de ampliación de derechos civiles y de regulación de mercado interno. Quien parecía capitalizar el déficit de la gestión "cristinista” era Mauricio Macri, jefe de gobierno 
de la Ciudad Autónoma de Buenos Aires y su ascendente partido PRO, de orientación centroderecha, con mucha llegada a los medios de comunicación y acompañado por las elites tecnocráticas y por buena parte de las capas medias del país (Vommaro et al., 2015; Vommaro, 2017).

Los resultados de la primera vuelta resultaron sorprendentes: la fórmula Scioli/Zannini alcanzó el $37,1 \%$ y la de Macri/Michetti, el 34,2\% (3). Las encuestas electorales publicadas previamente a la votación del 24 de octubre de 2015 no habían advertido el escenario de un empate técnico entre el candidato del FpV y el de Cambiemos. Si bien los sondeos especulaban con un posible balotaje, lo cierto es que los últimos resultados revelaban una "amplia ventaja" del candidato oficialista que lideraba la intención de voto en $37,1 \%$, seguido por Macri que se mantenía con una intención de voto del $26,2 \%$, de acuerdo a la encuestadora Poliarquía, contratada por el diario La Nación (4). En sintonía, la encuestadora Managment \& Fit, que trabajó para Clarín, señalaba que Scioli alcanzaba un $38,3 \%$ proyectando indecisos y Macri llegaría al $29,2 \%$ (5).

\section{Predebate}

\section{Producir el debate para la televisión}

Con la frustración histórica de no lograr un consenso en torno a los debates televisivos, un grupo de jóvenes empresarios y del CIPPEC crearon Argentina Debate, una iniciativa que buscó promover desde septiembre de 2014 la realización del primer debate televisivo (6).

El trabajo de Argentina Debate, que recibió el apoyo de más de 200 organizaciones de la sociedad civil y de expertos internacionales en debates presidenciales, se cristalizó en la presentación del formato de bien público que tendría el primer debate presidencial. Además, se presentaron un conjunto de requisitos: a. la participación de los candidatos presidenciales con un criterio amplio y pluralista; b. la realización en un lugar público de alto valor simbólico y prestigio, como la Facultad de Derecho de la Universidad de Buenos Aires (UBA) o la Biblioteca Nacional; c. garantizar el acceso igualitario a través de una coalición de medios de comunicación que cooperaran en la transmisión del debate; d. la inclusión de instancias de negociación y acuerdo transparentes y confiables en todas las partes; e. equilibrio de temas de agenda estratégica de desarrollo del país con temas coyunturales de interés para la sociedad; f. institucionalización del debate (6).

La firma del acuerdo sobre las reglas del debate, por parte de los equipos de campaña de los seis candidatos a la presidencia, y los temas que se acordaron para ser debatidos (educación e infancia, calidad institucional, desarrollo económico, y seguridad y derechos humanos) implicó un arduo trabajo para la ONG, pero significó el inicio de la etapa final para la realización del evento. La estrategia de acercamiento con los medios de comunicación, tan necesarios para amplificar el debate, también fue oportuna. Argentina Debate reconoció que sin ellos el debate 
no podría ser posible. En este sentido, fue fundamental el espaldarazo que dio la Asociación de Teleradiodifusoras Argentinas (ATA), la Asociación de Radiodifusoras Privadas Argentinas (ARPA) y los periódicos Clarín, La Nación, El Cronista, Editorial Perfil e Infobae. Con la prensa gráfica se trabajó en una agenda que tomó contenidos surgidos de los intercambios con distintas organizaciones de la sociedad civil e instituciones académicas (Acosta, 2016). A esto hay que sumar las intensas gestiones que los organizadores realizaron con los canales de televisión, para que el debate fuera transmitido en simultáneo. Canal 13 trató de persuadir a la ONG para tener la exclusividad.

Hacia junio de 2015, la consultora Ipsos-Mora y Araujo difundió una encuesta realizada en 1011 personas, residentes en 26 localidades del país, cuidando los criterios de representatividad de las distintas regiones y estratos poblacionales y con un error muestral del $+/-3,09 \%$. La misma reveló un par de datos interesantes: 1 . el $78 \%$ de los argentinos cree en la importancia de que se concrete un debate entre candidatos; en otras palabras, 8 de cada 10 encuestados pide que los contendientes intercambie públicamente sus ideas; 2 . un $71 \%$ miraría el debate en caso de ser televisado; 3 . en todos los casos, el porcentaje de personas que consideran al debate televisivo como "muy importante" no baja de los 51 puntos (7). Esto confirma la gran expectativa que señaláramos al principio del trabajo.

\section{La previa al duelo}

Ambos candidatos presidenciales que pasaron la primera vuelta ratificaron, luego de arduas negociaciones, que debatirían antes del balotaje. Sería una doble novedad: el primero que se daría a nivel nacional de la historia argentina y el primer debate televisado en esa situación política consolidada de dos candidatos a la presidencia.

Los equipos de guionado y ensayo para el evento estuvieron integrados en forma permanente, en el caso de Macri, por el jefe de campaña Marcos Peña, el secretario de medios de la Ciudad, Miguel de Godoy y su asesor "estrella", el ecuatoriano Jaime Durán Barba. También participaron algunos intelectuales y otros funcionarios de la Ciudad, encargados de suministrar ideas y datos. Con Scioli trabajó su jefe de gabinete, Alberto Pérez, el secretario de comunicación de la Provincia de Buenos Aires, Juan Courel, el presidente del Banco Provincia, Gustavo Marangoni y quien oficiaba de vocero Yago de Marta, un español poco conocido en nuestro medio que enseña retórica con métodos muy histriónicos.

Para el grupo macrista, Durán Barba redactó un briefing en el que afirmó concluyente que "En América Latina con los debates no se ganan votos. Se posicionan temas o personas". Anticipando los probables efectos de la contienda, subrayó que los temas no debían ser muchos y que sería eficaz si luego genera conversaciones sobre el mismo, si algo les parece interesante. En otro párrafo subrayó que "El debate es una pieza de teatro en la que hay que 
tener bien definidos los perfiles de los personajes". El asesor ecuatoriano recomendada básicamente a Macri que se mostrase "seguro de sí mismo", abonando la creencia "que va a ganar, que respeta a los presentes y toma nota de sus ideas para gobernar".

El texto cierra con una serie de anotaciones generales, la primera de las cuales es algo que Durán Barba (y otros consultores) repiten siempre: El debate se VE, no se oye. En consonancia con principios de la retórica clásica recomendó poner el acento en los dos extremos del debate: el principio, que es el que concentra mayor audiencia y atención y el final. A posteriori, Durán Barba dio mucha importancia al cierre que, según el equipo, es lo que formatea la imagen más contundente entre los periodistas. Su última escena fue con "estética romántica" por el "apasionado" beso con su esposa. Actuación menos llamativa que la de su contrincante Scioli, que hasta fue objeto de cierta ridiculización en las redes sociales mostrándolo como un voyeur del acto provocado por su contrincante.

En tanto el equipo de Scioli dedicó menos tiempo a su preparación. Fue más caótico, con muchas presencias rotativas en las reuniones y poco ensayo. Según los entrevistados, si bien el candidato escuchaba no "peloteaba" con ello, salvo en algunas ocasiones con Marangoni, encargado de representar el papel de Macri. Comentaron que Scioli escuchaba, pero fue poco permeable a consejos, sugerencias e intercambios con su equipo.

En el búnker del FpV advirtieron que el cruce con Macri podría ser una instancia clave para dar vuelta la tendencia, en la que corrían desde atrás, pese a que se había ganado la primera vuelta. En Cambiemos evaluaron que su táctica debía ser no equivocarse y evitar asumir riesgos mayores que, presentían, serían tomados por Scioli. El equipo de Macri sabía que, desde que se le había bajado la orden al candidato oficial de que no disponía de más recursos para la campaña, la decisión estratégica era enfatizar los contrastes mediante una campaña negativa.

\section{Debate}

\section{Huellas de lo dicho y actuado}

El debate televisado consistiría en intercambios verbales sobre temas previamente convenidos. En nuestra opinión, esos temas resultaban demasiado generales pese a que se había anexado una guía más específica, que ninguno de los contendientes tuvo en cuenta durante la emisión. La entidad organizadora estableció un "manual de estilo" que prescribía preceptos generales, protocolos ceremoniales, tratamiento audiovisual y tiempos de exposición, entre otras cuestiones que, en algunos casos, no llegaron a ejecutarse. Los tiempos fueron breves: cada candidato tenía dos minutos para exponer el tema, el otro candidato podía hacerle una pregunta en un minuto y el interrogado contaba con igual tiempo para responder; acto siguiente, el candidato que había preguntado volvía a tener un minuto para repreguntar y el 
otro candidato el mismo tiempo para responder y finalizar la secuencia. No se permitieron las interrupciones durante las exposiciones y tampoco los aplausos del público. El orden de exposición fue sometido a sorteo ante escribano público.

La duración del debate fue una hora y treinta y cuatro minutos, bastante breve si lo comparamos por ejemplo con los debates "cara a cara", al aire libre, sostenidos entre Abraham Lincoln y Stephen A. Douglas en 1858. Además, advertimos que el debate argentino se desarrolló bajo una estructura muy rígida que redundó en cierta monotonía durante su desarrollo.

Cada uno de los oradores estaba más pendiente de su propio guión que de la escucha atenta de su contrincante. La enunciación provenía de la estrategia elegida para las afirmaciones, ataques y defensas que se había practicado antes de subir al proscenio. Asimismo, los candidatos estabas imbuidos en regular el papel actoral que habían elegido y ensayado; por caso, mostrarse tranquilos o vigorosos. En consecuencia, las intervenciones resultaron demasiado previsibles.

La dinámica del debate argentino fue diferente a la de Estados Unidos u otros países, donde varios periodistas preguntan y hay una participación directa de público anónimo. De adoptarse esa modalidad, los equipos de Macri y Scioli probablemente nunca se hubiesen puesto de acuerdo. Los organizadores reconocieron que fue el debate posible.

\section{Una mirada al debate y su escena}

Si bien al emprender este trabajo dijimos que no abordaríamos un análisis del discurso de los candidatos, creemos necesario hacer una breve referencia a él. En tal sentido, ofrecemos una exploración a partir de algunos señalamientos:

1. Los dos contrincantes distribuyeron, con alguna diferencia, líneas discursivas entre afirmación, ataque y defensa. Scioli superó en tiempo de ataques a Macri, congruente con la insistencia discursiva de los "dos modelos" antagónicos puestos en juego que articulaban con la "campaña negativa" o, según sus adversarios, "del miedo".

2. Macri y Scioli coincidieron en que sus escenas de apertura se dirigieran a la mirada a cámara reforzando la estrategia del eje $\mathrm{O}-\mathrm{O}$ (los ojos en los ojos). En todas las negociaciones entre equipos de debate, es clásico ser muy escrupulosos en el cuidado de la composición de los planos de los oponentes o en su secuencia. Esto por la simple razón que la gestualidad del que aparentemente escucha puede descalificar gestualmente al que hace uso de la palabra. Al parecer eso se contempló para este debate. Hemos observado que Macri tuvo un dominio del espacio televisivo superior al de Scioli.

3. En proxémica quinésica, Macri combinó mejor los traslados y giros corporales desde la mirada a cámara a su contrincante, con una postura relajada. Contrariamente, Scioli sólo miraba a su contrincante cuando exponía. En esta categoría quinésica, Scioli ponía energía 
corporal -a veces demasiada para la televisión- para enfatizar el yo afirmativo, intenso en léxico pero confuso en proxémica acústica: lo hacía con mucha rapidez y respiraba mal. Macri lo hacía con mayor lentitud aunque su modulación no tenía demasiado cambio de tonalidades (alto, bajo, enfatización).

Para recapitular, comprobamos la distribución equilibrada entre afirmación, ataque y defensa en Macri. Hubo ataque con formulación léxica algo innovadora. Por ejemplo, al comienzo del encuentro, el Jefe de gobierno de la Ciudad buscó "pegarle" a Scioli con situaciones muy controvertidas. En la proxémica léxica usó más el par nosotros/ustedes (en referencia a la administración kirchnerista). Un par de pasajes convalidan esta afirmación:

-Daniel: ¿en qué te has transformado? ¿O en qué te han transformado? Parecés un panelista de "6, 7, 8", diciendo una cantidad de mentiras que escuchamos hace años.

-Primero quiero aclararte. Daniel: vos no sos el cambio; vos decidiste, elegiste ser la continuidad. Elegiste estar con Zannini, con Aníbal Fernández, con Milagro Sala, vos elegiste estar con Axel Kicillof, con Máximo Kirchner. Nosotros somos el cambio. Nosotros queremos venir a gobernar diciendo la verdad, escuchando, dialogando, respetando la independencia de los poderes. Eso es lo que va a generar confianza, no todas estas mentiras que estás diciendo.

Scioli utilizó más recurrentemente el ataque en cada tema en mayor cantidad que Macri. En proxémica léxica combinó el yo, con el yo/ustedes. Su expresión corporal y semblante lo mostró algo nervioso al principio, con muchas dificultades para poder cumplir con los tiempos y en varias oportunidades se excedió en los tiempos, tuvo que dejar inconclusa la exposición. Sus intervenciones continuaron la línea de la denominada "campaña del miedo" que implicó a Macri como el "regreso a tiempos pasados", "devaluación", "ajuste", "no intervención del Estado".

\section{Posdebate}

\section{Posfacto}

Si se analiza el debate a través de varias repeticiones pueden ampliarse algunos aspectos no considerados en el acápite anterior, pero que terminan de hilar el conjunto de aspectos comunicacionales y político-culturales del objeto de estudio. En síntesis, de la observación y la notación del debate, los documentos y las entrevistas con los integrantes de los equipos, podemos sostener:

1. Desde el punto de vista de los candidatos, cada uno se sintió "ganador", en el entendimiento que ambos cumplieron con sus objetivos trazados. Ninguno expresó disconformidad con su 
actuación, al menos públicamente. Empero, en la intimidad del equipo de Scioli se reconoció "que se lo vio nervioso e inseguro".

2. Del análisis de contenido de la emisión podemos sostener que el nivel de debate político no deparó casi ninguna sorpresa. La argumentación fue pobre en ambos candidatos. El debate no tuvo demasiados momentos de climax, factor que representa el punto álgido de interés y tensión para el espectador, y tampoco fue posible constatar un continuum dramático que derivó en un déficit de suspense.

3. Macri se mostró más enérgico, decidido y "canchero" (sangrón). Apareció más "distendido" que su oponente, cumplió en general con los tiempos acordados y no se le llamó la atención sobre su exceso. Logró, en términos emocionales, controlarse. Scioli lució algo agobiado, poco entusiasmado y hasta enojado. Su tono de discurso se centró en "mantener a los propios" más que a persuadir indecisos; el mensaje al paradestinatario no tuvo contundencia.

4. La repercusión mediática generó opiniones más favorables a Macri en cuanto a su actitud de tranquilidad. Aunque siempre se calificó la contienda como una suerte de empate, ya que cada uno había logrado su cometido y, en definitiva, ninguno había incurrido en errores, a pesar de la contundencia que había tenido el beso "espontáneo" de la esposa de Macri tras finalizar el debate.

5. El debate atrajo la atención de los medios y sus públicos y consiguió picos de más de 53 puntos de rating, alcanzando 5,5 millones de televidentes. Las gerencias de contenidos de las diferentes televisoras diseñaron "programas satélites" destinados a seguir el "antes" y el "después" del debate. Toda la televisión argentina se puso al servicio del debate presidencial.

6. Las redes sociales también cosecharon números interesantes: a. en Google, las búsquedas relacionadas a Scioli y Macri se triplicaron durante ese domingo y llegaron al primer puesto en sus tendencias; b. durante el debate, en Twitter se escribieron 12 mil tuits por minuto; además, el hashtag \#ArgentinaDebate superó las 1,8 millones de veces y fue la tendencia número uno de esta red social en el mundo; c. en Facebook, la fan page de Scioli (con 1,4 millones de seguidores) realizó un posteo hacia el final del encuentro y obtuvo 36 mil "Me gusta"; en tanto Macri (con 2,6 millones de seguidores) posteó cinco veces y logró 364 mil "Me gusta" (Acosta, 2016).

\section{Algunas conclusiones}

Argentina Debate se sintió satisfecha de haber logrado "esta fotografía que ayuda a la democracia" y que abrió la posibilidad de una tradición de debates presidenciales en nuestro país. A pesar de las limitaciones del primer debate entre candidatos presidenciales, reconocemos el gran mérito. 
Dentro de esas limitaciones, nosotros creemos que el debate sólo sirvió en términos de acto propagandístico para reforzar las posiciones previas establecidas, que tuvieron algunas variaciones a lo largo de la campaña. Esto derivó en el poco debate de ideas, con mucho espacio para las chicanas políticas y demás artilugios que demanda la democracia de audiencia. En un escenario tan guionado, no hubo lugar para que irrumpiera lo político.

En definitiva, ante tanta expectativa se consumó una competencia simbólica y verbal en la que el resultado fue que no hubo vencedor ni vencido neto. El reto ahora es mantener vigente esta nueva práctica y esperar que en los próximos debates los candidatos puedan exponer sus programas de gobierno y, fundamentalmente, dialogar con los "contrincantes". Después de todo, sólo con información de quienes aspiran a representarlos, los ciudadanos pueden tomar mejores decisiones al momento de votarlos.

\section{Notas}

(1) Fuente: http://edant.clarin.com/diario/2003/05/02/p-00901.htm

(2) Poco antes del 10 de diciembre de 2015, Clarín publicó en su portal una nota titulada "Cristina deja la Casa Rosada con su imagen negativa en alza". Con datos de una encuesta de M\&F, el diario destacó que la presidenta "terminará su mandato con un $55,6 \%$ de "desaprobación" en la gestión de su gobierno". Fuente: http://www.clarin.com/politica/Cristina_Kirchner-Casa_Rosada-fin_de_ciclo-imagen_negativa-gobierno-kirchnerismoencuesta_0_1480652522.html

(3) Fuente: http://www.electionresources.org/ar/presidente.php?election=2015

(4) La Nación, 11 de octubre de 2015.

(5) Fuente: http://www.clarin.com/politica/Encuesta-Management_-_Fit-perspectiva-balotaje_0_1450654978.html

(6) Fuente: http://www.argentinadebate.org/novedades/junto-a-expertos-internacionales-argentina-debate-presento-elformato-del-primer-debate-presidencial-argentino/

(7) Fuente: http://www.parlamentario.com/noticia-82951.html.

(8) Los contendientes centraban la disputa verbal en tópicos sobre esclavitud, moral y valores y se encontraron siete veces seguidas en siete estados diferentes de la geografía estadounidense. El primer orador podía extenderse hasta sesenta minutos, luego su contrincante tenía noventa minutos y, por último, quien había hablado primero tenía otros 30 más. Había público que no se movía durante toda su realización.

\section{Bibliografía}

Acosta, M. (2016). La sociedad civil y el primer debate presidencial en Argentina. Revista Marco, 2, pp. 111-130.

Blaustein, E. (2013). Años de rabia. El periodismo, los medios y las batallas del kirchnerismo. Buenos Aires: Ediciones B. 
Boorstin, D. (2012). The Image: A Guide to Pseudo-Events in America. New York: Random House.

Campolongo, C. et al. (2009). Retenciones y protestas contadas en dos. Un análisis de las columnas de opinión de Eduardo van der Kooy y Joaquín Morales Solá. Buenos Aires: Instituto de Altos Estudios Juan Perón.

Canel, M. J. (2008). Debatir para ganar. Nueva Revista de Política, Cultura y Arte, 115. Recuperado de http://www.nuevarevista.net/articulos/debatir-para-ganar

Castells, M. (2010). Comunicación y Poder. Buenos Aires: Alianza.

Crespo, I. y del Rey Morató, J. (2013). Comunicación política y campañas electorales en América Latina. Buenos Aires: Biblos.

Debray, R. (1999). El Estado seductor: las revoluciones mediológicas del poder. Buenos Aires: Manantial.

Del Rey Morató, J. (1996). Democracia y posmodernidad. Teoría General de la Información y Comunicación Política. Madrid: Editorial Complutense.

Edelman, M. (1991). La construcción del espectáculo político. Buenos Aires: Manantial.

Gutiérrez Rubí, A. (2015). La transformación digital y móvil de la comunicación política. Barcelona: Ariel.

Hershey, M. (2001). The Campaing and the Media. En The election of 2000: Reports and Interpretations. New York: Chatam House.

Isolatus, P. (2011). Analyzing presidential debates. Functional theory and Finnish political Communicational Culture. Nordicom Review, 32, pp. 31-43.

Krippendorff, K. (1990). Metodología de análisis de contenido. Teoría y práctica. Barcelona: Paidós.

Landi, O. (1992). Devórame otra vez. Qué hizo la televisión con la gente: qué hace la gente con la televisión. Buenos Aires: Planeta.

Lazarsfeld, P. et al. (1960). El pueblo elige: estudio del proceso de formación del voto durante una campaña presidencial. Buenos Aires: Ediciones 3.

Luengo, O. (2011). Debates electorales en televisión: una aproximación preliminar a sus efectos inmediatos. Revista Española de Ciencia Política, 25, pp. 82-96.

Luengo, O. y Marín, J. (2009). Liderazgo y debates electorales. IX Congreso Español de Ciencia Política, Aecpa, Málaga.

Mandoki, K. (1994). Prosaica: introducción a la estética de lo cotidiano. México: Grijalbo.

Manin, B. (1992). Metamorfosis de la representación. En ¿Qué queda de la representación política? Caracas: Nueva Sociedad.

Muraro, H. (1998). Poder y comunicación. Buenos Aires: Letra Buena.

O’Donnell, G. (1994). Delegative Democracy. Journal of Democracy, 5(1), pp. 55-69.

Peri, Y. (2004). Telepopulism. Media and Politics in Israel. Stanford: Stanford University Press. 
Plasser, F. y Plasser, G. (2002). La campaña global. Los nuevos gurúes del marketing político en acción. Buenos Aires: KAS/Temas.

Reinemann, C. y Wilke, J. (2007). It's the debates, stupid! How the introduction of televised debates changed the portrayal of chancel or candidates in the German press, 19492005. The International Journal of Press/Politics, 12(4), pp. 92-111.

Ruiz, F. y Alberro, H. (2012). Olas de debates electorales en América. Luces y sombras de un avance democrático. Medios Latinos. Recuperado de http://www.kas.de/upload/auslandshomepages/medioslatinos/debates_electorales.pdf

Sampedro, V. (2000). Opinión pública y democracia deliberativa: medios, sondeos y urnas. Madrid: Istmo.

Sartori, G. (1998). Homo videns: La sociedad teledirigida. Madrid: Taurus.

Sartori, G. (2003). Videopolítica: medios, información y democracia de sondeo. Madrid: FCE.

Verón, E. (1997). Esquema para el análisis de la mediatización. Revista Diálogos de la Comunicación, 48, pp. 9-16.

Vommaro, G. (2017). La larga marcha de Cambiemos. La construcción silenciosa de un proyecto de poder. Buenos Aires: Siglo XXI.

Vommaro, G.; Morresi, S. y Belloti, A. (2015). Mundo Pro. Buenos Aires: Planeta.

Waisbord, S. (1997). Prácticas y precios del proselitismo presidencial. Apuntes sobre medios y campañas electorales en América Latina y Estados Unidos. Contribuciones, 2, pp. 159182.

Wolton, D. (1999). Sobre la comunicación: una reflexión sobre sus luces y sus sombras. Madrid: Acento. 